Journal of Advanced Research in Fluid Mechanics and Thermal Sciences

\title{
Structural, Thermal and Optical Properties of Rare Earth Doped Lead- Tellurite Oxide Glasses
}

\author{
W. L. Fong ${ }^{1}$, Sharudin Omar Baki ${ }^{2,}$, N. M. Arifin², Yaakob Mansor², Ahmad Nazri², Bashar Khudhair \\ Abbas $^{1}$ \\ 1 Wireless and Photonic Network Research Centre, Faculty of Engineering, Universiti Putra Malaysia, 43400 UPM Serdang, Selangor, Malaysia \\ Centre of Foundation Studies for Agricultural Science, Universiti Putra Malaysia, 43400 UPM Serdang, Selangor, Malaysia
}

\section{ARTICLE INFO}

\section{Article history:}

Received 23 October 2020

Received in revised form 9 February 2021

Accepted 15 February 2021

Available online 22 March 2021

\section{Keywords:}

Tellurite glasses; XRD; absorption; Raman; optical energy

\section{ABSTRACT}

Structural, thermal and optical properties of lead-tellurite oxide glasses consisting $\mathrm{TeO}_{2}$ - $\mathrm{PbO}-\mathrm{Bi}_{2} \mathrm{O}_{3}-\mathrm{Er}_{2} \mathrm{O}_{3}$, synthesized by high temperature melt-quenching-thermal annealing method were investigated in this study. The role of rare-earth element, erbium ion as dopant into the host glass has affected physically, thermally and optically of the glasses. The amorphous nature of the glasses was confirmed by XRD ( $x$-ray diffraction). Thermal exo-endothermic event profiles clarify its glass transformation temperature $T_{\mathrm{g}}$, crystallization temperature $T_{\mathrm{x}}$, and melting temperature $T_{m}$ are exist. Both UV-Vis-NIR optical absorption and Raman spectroscopy have revealed optical energy gap changes due to the structural deformation by the erbium ions. Related obtained glass parameters such as polarizability, refractive indices and metallization criterion were also explained further in this study.

\section{Introduction}

Heavy metal oxides (HMO) glasses recently have attracted much attention for photonic and radiation shielding applications due to their excellent physical and optical properties [1-2]. Independent oxide tellurite glass does not have the ability to form glass structure easily under normal conditions. Thus, via incorporation of chemical modifiers like alkali oxides, alkaline-earth oxides, or transition-metal oxides, may improve its glass-forming ability forming multicomponent oxide based tellurite glasses with high glass stability [3-5].

In this study, erbium incorporation as dopant into tellurite oxide base glass consisting heavy metal lead and bismuth oxides $\left(\mathrm{TeO}_{2}-\mathrm{PbO}_{-} \mathrm{Bi}_{2} \mathrm{O}_{3}\right)$ glasses were synthesized and characterized for structural, thermal and optical properties. Lead oxide, $\mathrm{PbO}$ acts as glass modifier to form more stable glass, enhancing linear and nonlinear refractive indexes due to its massive mass, low field strength and high polarizability [6]. $\mathrm{Bi}_{2} \mathrm{O}_{3}$ also may act as conditional glass formers and by the addition of $\mathrm{PbO}$, the formation into a more stable glass will become more possible [7]. Our objectives in this work are to produce HMO tellurite-based glass and explore its potential for optical applications.

\footnotetext{
* Corresponding author.

E-mail address: sharudinomar@upm.edu.my
}

https://doi.org/10.37934/arfmts.81.2.5258 


\section{Methodology}

All starting chemicals are oxide powders of tellurite $\left(\mathrm{TeO}_{2}: 99.9995 \%\right.$, Strem Chemicals), lead (PbO: 99.97\%, American Elements), bismuth $\left(\mathrm{Bi}_{2} \mathrm{O}_{3}: 99.9 \%\right.$, Sigma Aldrich) and erbium $\left(\mathrm{Er}_{2} \mathrm{O}_{3}: 99.9 \%\right.$, American Elements). The glass sample was synthesized by substitutional replaces $\mathrm{Bi}_{2} \mathrm{O}_{3}$ with $\mathrm{Er}_{2} \mathrm{O}_{3}$ into host glass with mol\% composition of $60 \mathrm{TeO} 2-35 \mathrm{PbO}-(5-\mathrm{y}) \mathrm{Bi}_{2} \mathrm{O}_{3}-\mathrm{yEr} \mathrm{O}_{3}, \mathrm{y}=0$ (G1 Host glass), 0.5 (G2 glass), 1 (G3 glass), 1.5 (G4 glass). Chemicals were carefully weighed and uniformly mix before melted in a closed-lid alumina crucible in an electrical furnace for an hour at $1000^{\circ} \mathrm{C}$. Melt-quenching annealing technique is applied which molten glass was quenched onto a preheated stainless steel plate mold and immediately transferred into an annealing furnace at $200^{\circ} \mathrm{C}$ for 2 hours. Glass sample with dimension of $2 \mathrm{~cm}$ diameter and $3 \mathrm{~mm}$ thickness were obtained and polished for optical measurement.

Characterization of glass structure involved X-ray diffraction (XRD) analysis by Xpert Highscore PANalytical X-ray diffractometers while its density measurement is based on Archimedes principle using the distilled water as an immersion liquid. Thermal measurement is through DSC-Mettler Toledo $822 \mathrm{E}$ analyzer in the temperature range of $25-650{ }^{\circ} \mathrm{C}$, at heating rate of $10 \mathrm{~K} \mathrm{~min}^{-1}$, under $\mathrm{N}_{2}$ gas ambient. Raman spectroscopy was performed via Witec Confocal Microscope (Alpha 300R) system using $532 \mathrm{~nm}$ excitation source within the range of $100-1000 \mathrm{~cm}^{-1}$. For optical study, absorption analysis was obtained through Jasco V570 UV/VIS/NIR spectrophotometer in the wavelength range of $350-2000 \mathrm{~nm}$.

\section{Results and Discussion}

\subsection{X-ray Diffraction and Raman Spectroscopy}

The obtained XRD profile of the HMO host glass in the range of $10^{\circ} \leq 2 \theta \leq 70^{\circ}$ is shown in Figure 1. A broad scattering range without any existing sharp peaks are clearly represents a typical long range structural disorder confirms the glass in this study is amorphous in nature (similar XRD profiles were obtained for all doped glasses G2, G3 and G4).

Raman spectroscopy provides optical analysis for the structure and functional groups of the studied glass. The obtained Raman spectra of the fabricated host and erbium doped glass are shown in Figure 2. Deconvolution of the Raman spectra accordingly into several main symmetric Gaussian bands around $700-800 \mathrm{~cm}^{-1}, 300-700 \mathrm{~cm}^{-1}$ and below $300 \mathrm{~cm}^{-1}$, were performed to identify corresponding vibrational mode of certain $\mathrm{TeO}_{2}$ polyhedral coordination. As general low frequency band (less than $300 \mathrm{~cm}^{-1}$ ) is attributed to the collective modes of local structures and heavy metal vibrational modes while the intermediate $\left(300-700 \mathrm{~cm}^{-1}\right)$ is ascribed to the deformation of vibrational modes of a glass network with bridged oxygen and high frequency region (above 700 $\mathrm{cm}^{-1}$ ) is related to the stretching vibrational modes of the glass network former [8]. Observed strong band around $730 \mathrm{~cm}^{-1}$ is attributed to weak stretching mode of the $\left[\mathrm{TeO}_{3}\right]$ tp (trigonal pyramids) units and (or) intermediate coordination of $\left[\mathrm{TeO}_{3+1}\right]$ units associated with non-bridging oxygens (NBOs) in the glasses, are found relatively more pronounce than its other neighboring bands [9]. This band among highest vibrational energy observed in the Raman spectrum which representing phonon energy of the host glass. It is important for host materials to have relatively low phonon energy for obtaining high efficiency lasers and fibre amplifiers since it reduces the non-radiative transitions and enhance the luminescence efficiency of the dopant ions. Raman band around $100 \mathrm{~cm}^{-1}$ is indicates high possibility due to the presence of the HMO elements of lead and bismuth in the studied glasses. As compared to host glass, the erbium doped glasses have shown an abrupt reduction of the high frequency region of the Raman spectra. The emerging of lower frequency band around $350 \mathrm{~cm}^{-1}$ and 
another peak around $250 \mathrm{~cm}^{-1}$ could be also assigned to the formation of another [ $\left[\mathrm{TeO}_{3}\right]$ tp structural units with NBOs and (or) Te-O-Pb linkages and $\mathrm{Er}-\mathrm{O}$ bonds respectively [10]. (due to spectrum deconvolution and clarity purposes only $\mathrm{G} 1$ and $\mathrm{G} 4$ glasses are shown here for comparison. Both doped glasses $\mathrm{G} 2$ and $\mathrm{G} 3$ also shown similar Raman band profiles). Thus, it can be concluded progressive modification of the $\mathrm{TeO}_{2}$ glassy network occurs in the system due to erbium ion.

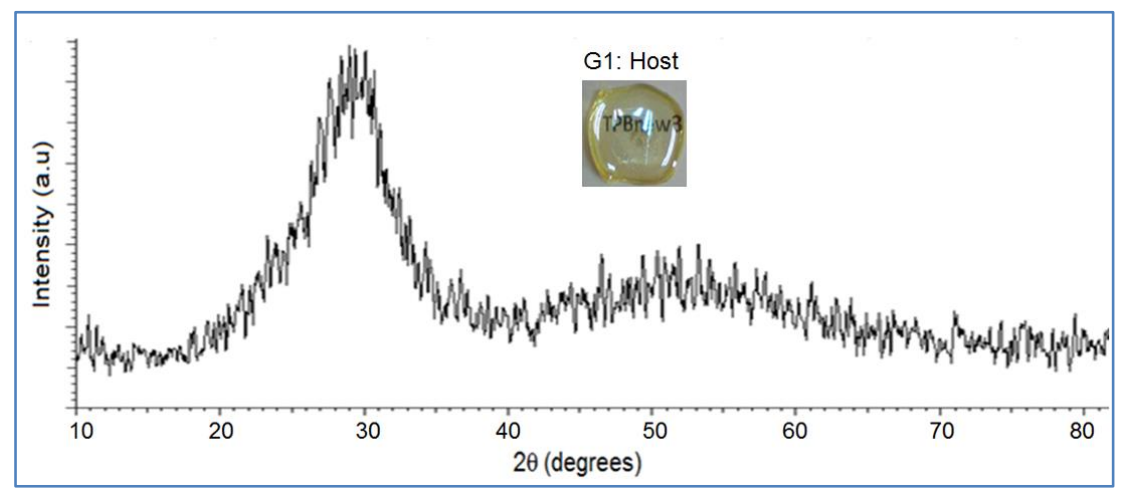

Fig. 1. XRD profile of host, G1 HMO tellurite glass
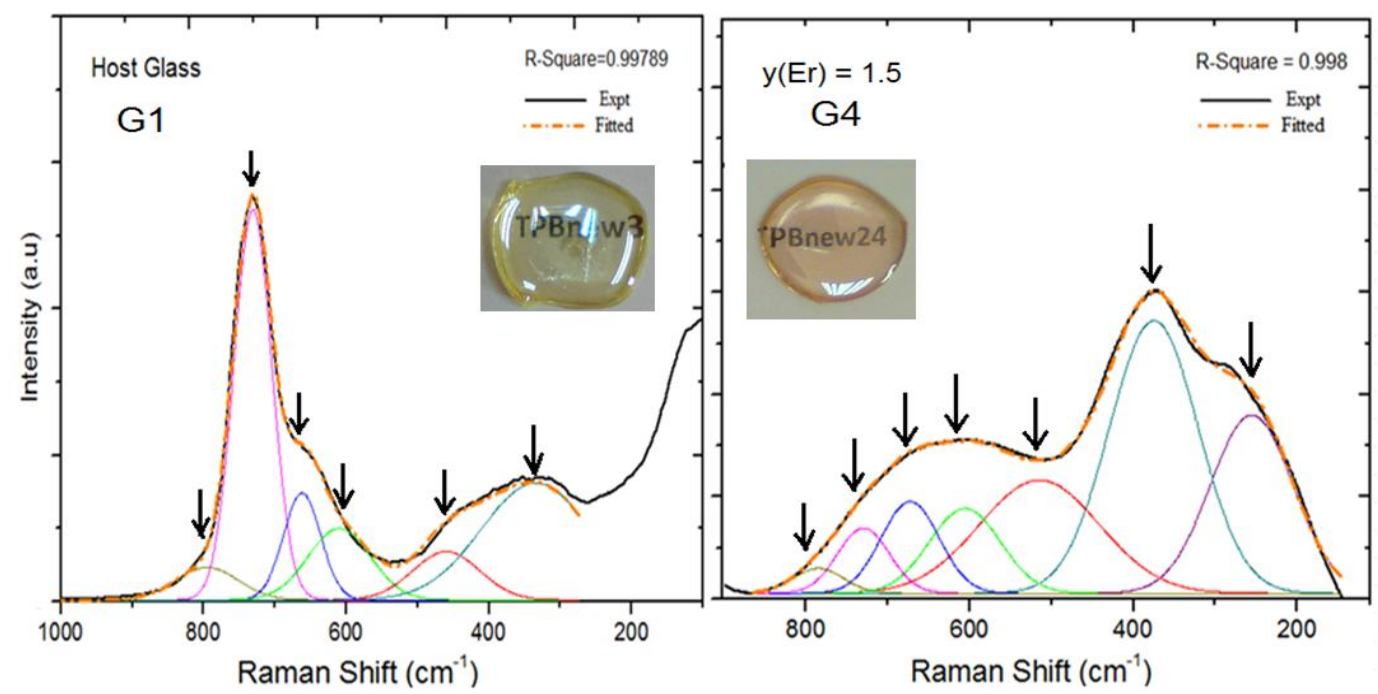

Fig. 2. Raman spectra (with deconvolution) of the host and erbium doped HMO tellurite glasses

\subsection{Thermal Analysis}

Figure 3 depicts the thermal profiles for host $\mathrm{G} 1$ glass and its corresponding erbium doped G2 $\mathrm{HMO}$ glass. As seen in the thermal profile all three common characteristic events are exist. The glass transformation event $T_{\mathrm{g}}$ occurred at $277{ }^{\circ} \mathrm{C}$ and $285^{\circ} \mathrm{C}$, for $\mathrm{G} 1$ and $\mathrm{G} 2$ glasses respectively, with $T_{\mathrm{g}}$ increases after erbium ion incorporation. Several crystallization phases are formed in these glasses but only the lowest crystallization temperature event is considered in discussing glass stability. Thus, the lowest $T_{\mathrm{x}}$ occurred at $325^{\circ} \mathrm{C}$ and $327^{\circ} \mathrm{C}$ for $\mathrm{G} 1$ and $\mathrm{G} 2$ glasses respectively. The melting events are clearly represented by the sharp endotherm peak at $550{ }^{\circ} \mathrm{C}$ and $555{ }^{\circ} \mathrm{C}$, for $\mathrm{G} 1$ and $\mathrm{G} 2$ glasses respectively. 


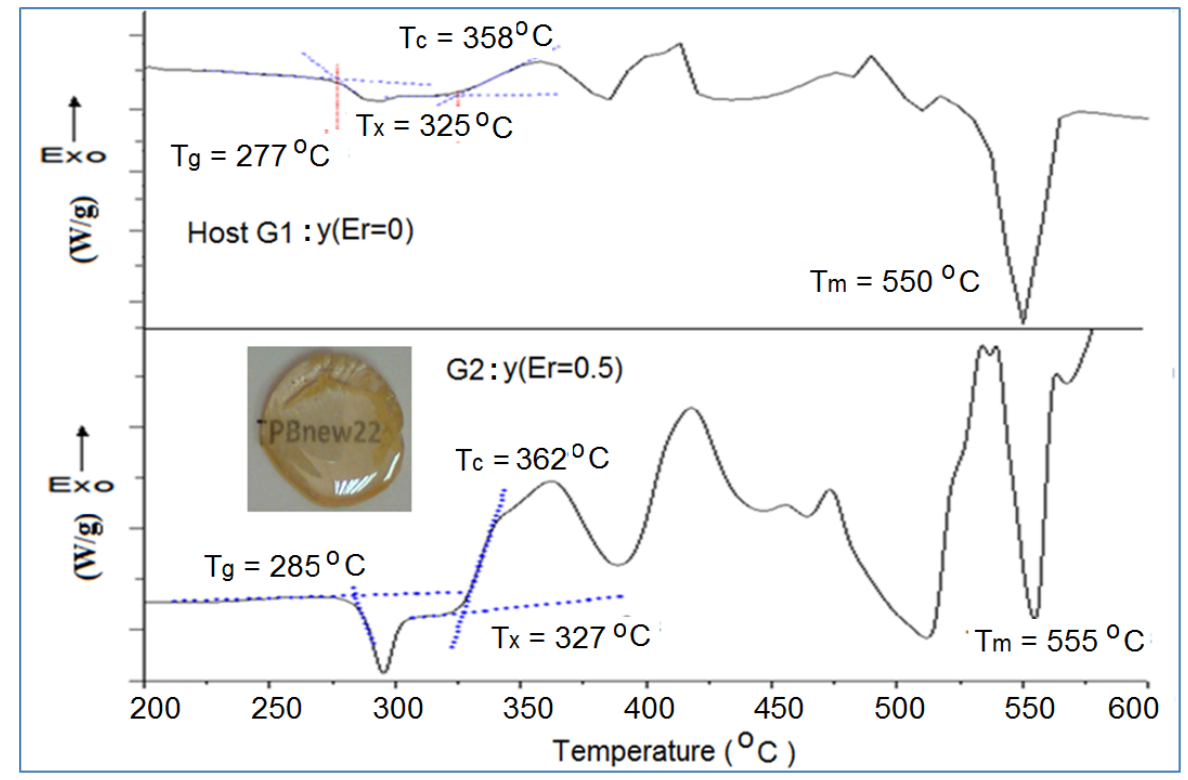

Fig. 3. Thermal profile for host and erbium doped HMO tellurite glasses

\subsection{Absorption Spectra and Judd-Ofelt Analysis}

Visible and near-infrared optical absorption spectra of the erbium doped HMO glasses are depicted in Figure 4. As seen strong absorption around $400 \mathrm{~nm}$ is a well-known glassy nature characteristic due to fundamental absorption edge of the host matrix in the ultraviolet region. The absorption coefficient, $\alpha$ as function of photon energy, $h v$ for direct and indirect optical transitions is given as below [11]

$\alpha(v)=\frac{A\left(h v-E_{o p t}\right)^{n}}{h v}$

where $A$ is constant (or also referred as Tauc factor), $E_{\text {opt }}$ is the optical energy gap and $\mathrm{n}$ is a constant which determines type of the interband transition ( $n=2$ refers indirect allowed transition and $n=1 / 2$ for direct allowed transition). Tauc plot for the optical energy gap analysis of the amorphous materials is shown in Figure 5.

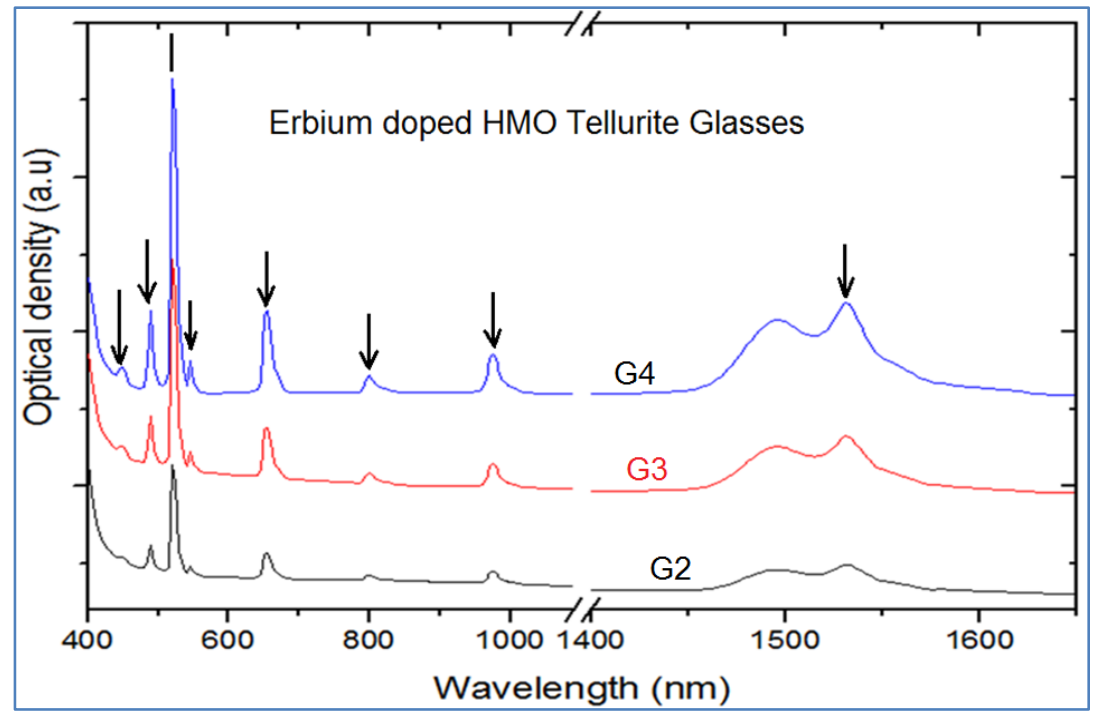

Fig. 4. Absorption spectra of the erbium doped HMO tellurite glasses 


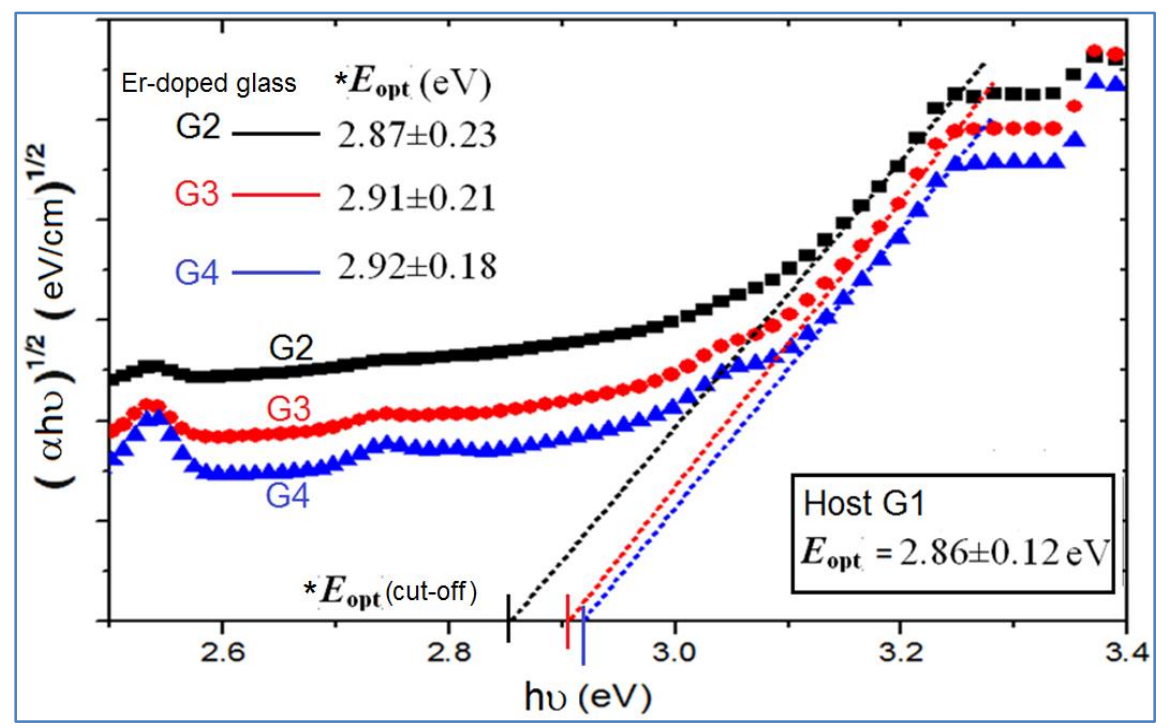

Fig. 5. Tauc's plot for absorption as a function of photon energy for the HMO tellurite glasses

Urbach energy, $\Delta E_{U}$ value often related to the disorder amorphous nature of the glass matrix. Generally, this energy refers to optical transition between the localized tailed states adjacent to the valence band and conduction band extended into the band gap [11]. Its reduction as erbium after erbium incorporation suggested less number of structural defects and degree of disorder in the glass matrix. As observed in Table 1, wider optical energy gap were produced which correlated smaller width for both valence and conduction bands. Such condition explained the increment value of $M$ which decreases the metallicity characteristic of the glasses. Such increment in optical energy gap is also explained due to less number of NBO formations within the glass network [12]. As seen in Table 1 both polarizability and refractive index reduction value trends after erbium addition explained less ionic bonds formation by forming more bridging oxygen (BO) network within the glass matrix. The structural changes from the transformation have caused the formation of a strong covalent bond (BO's) from the weaker ionic bond (NBO's) which increased the both $T_{g}$ and $T_{c}$ values [19]. The glass network structure is more compact represented by molar volume decrement with denser glass formation.

Table 1

Summary of physical and optical properties for G1-G4 synthesized HMO tellurite glasses

\begin{tabular}{lllll}
\hline Physical and Optical Property & $\mathrm{G} 1$ & $\mathrm{G} 2$ & $\mathrm{G} 3$ & $\mathrm{G} 4$ \\
\hline Molecular Weight, $M(\mathrm{~g} / \mathrm{mol})$ & 197.2 & 196.8 & 196.3 & 195.9 \\
Density, $\rho\left(\mathrm{g} / \mathrm{cm}^{3}\right)$ & 6.8622 & 6.8497 & 6.8810 & 6.8738 \\
Refractive index, $n_{D}(589.3 \mathrm{~nm})$ & 2.4358 & 2.4330 & 2.4217 & 2.4190 \\
Molar volume, $V_{m}\left(\mathrm{~cm}^{3} / \mathrm{mol}\right)$ & 28.734 & 28.726 & 28.534 & 28.503 \\
${ }^{* a}$ Polarizability, $\alpha_{m}\left(\times 10^{-24} \mathrm{~cm}^{3}\right)$ & 7.0905 & 7.0810 & 7.0039 & 6.9889 \\
$*$ beflection loss, $R_{L}(\%)$ & 17.46 & 17.42 & 17.26 & 17.22 \\
*c Metallization criterion, $M$ & 0.3782 & 0.3788 & 0.3814 & 0.3821 \\
Optical energy gap, $E_{\mathrm{opt}}(\mathrm{eV})$ & 2.86 & 2.87 & 2.91 & 2.92 \\
Urbach energy, $\Delta U(\mathrm{eV})$ & 0.16 & 0.18 & 0.15 & 0.14 \\
$\Omega_{2}\left(\times 10^{-20} \mathrm{~cm}^{2}\right)$ & - & 4.865 & 5.093 & 4.680 \\
$\Omega_{4}\left(\times 10^{-20} \mathrm{~cm}^{2}\right)$ & - & 1.314 & 1.386 & 1.446 \\
$\Omega_{6}\left(\times 10^{-20} \mathrm{~cm}^{2}\right)$ & - & 1.107 & 1.069 & 1.038 \\
\hline
\end{tabular}

*Note: $a, b$, and c are referred in [16], [17], and [18] respectively 
As shown in Figure 4, the absorption band of erbium ion designated at 452, 488, 524, 544, 654, 800,980 and $1533 \mathrm{~nm}$ are associated with the transition from the ground state $4 \mathrm{I}_{15 / 2}$ to the excited state $4 \mathrm{~F}_{5 / 2}, 4 \mathrm{~F}_{7 / 2}, 2 \mathrm{H}_{11 / 2}, 4 \mathrm{~S}_{3 / 2}, 4 \mathrm{~F}_{9 / 2}, 4 \mathrm{I}_{9 / 2}, 4 \mathrm{I}_{11 / 2}, 4 \mathrm{I}_{13 / 2}$ respectively. These bands are requirement in Judd-Ofelt analysis where the information pertaining to the local structure and bonding nature of the rare-earth ions within the glass host matrix are predicted. Further detailed explanations on the comprehensive analysis can be found in our previous works elsewhere [13]. The calculated JO intensity parameters $\Omega_{2}$, value is known related to symmetry of the glass host (short-range effect) which represents the ligand field structural formation surrounding the erbium ions within the glass matrix (covalency of the RE-metal ligand). In general larger $\Omega_{2}$ value indicates higher degree covalency of the Er-O bond. The $\Omega_{6}$ value also interpreted this behavior but in opposite way [14]. As seen in the table, reduction in $\Omega_{6}$ values resembles enhancement of the Er-O covalency as mentioned in Raman spectra [15]. Increment in optical band gap energy values with increasing of erbium ion content is associated with the reduction of non-bridging oxygen (NBO) which attributed by drastic reduction of the high frequency Raman band. This confirmed both Te-O-Pb linkages and Er-O bonds are dominant species in the doped glasses.

\section{Conclusions}

This work has been successfully investigating structural and spectroscopic behaviors of transparent and stable erbium doped HMO tellurite glasses. The high refractive index host glass is confirmed amorphous in nature. The structural of the studied glasses have presented significant structural deformation of the $\mathrm{TeO}_{2}$ glassy network or [TeO4]bi-pyramid into $\mathrm{TeO}_{2}$ polyhedral consisting $\left[\mathrm{TeO}_{3}\right]$ tp (trigonal pyramids) units and (or) intermediate coordination of $\left[\mathrm{TeO}_{3+1}\right]$ (or distorted TeO4) units associated with non-bridging oxygens (NBOs) through Raman spectral studies. Increment of the optical energy gap, strong Er-O covalency and progressive BO formations were established from optical absorption and $\mathrm{JO}$ analysis due to erbium ions incorporation into the $\mathrm{HMO}$ tellurite glasses.

\section{Acknowledgement}

The author gratefully acknowledged University Putra Malaysia and Ministry of Higher Education Malaysia through financial support GPB-9554200.

\section{References}

[1] Kaky, Kawa M., M. I. Sayyed, Farah Laariedh, Alyaa H. Abdalsalam, H. O. Tekin, and S. O. Baki. "Stuctural, optical and radiation shielding properties of zinc boro-tellurite alumina glasses." Applied Physics A 125, no. 1 (2019): 1-12. https://doi.org/10.1007/s00339-018-2329-3

[2] Sayyed, M. I., Ali A. Ati, M. H. A. Mhareb, K. A. Mahmoud, Kawa M. Kaky, S. O. Baki, and M. A. Mahdi. "Novel tellurite glass (60-x) TeO2-10GeO2-20ZnO-10BaO-xBi2O3 for radiation shielding." Journal of Alloys and Compounds 844 (2020): 155668. https://doi.org/10.1016/i.jallcom.2020.155668

[3] Hu, Xiao, Guillaume Guery, Joshua Boerstler, J. David Musgraves, Don Vanderveer, Peter Wachtel, and Kathleen Richardson. "Influence of $\mathrm{Bi} 2 \mathrm{O} 3$ content on the crystallization behavior of TeO2-Bi2O3-ZnO glass system." Journal of Non-Crystalline Solids 358, no. 5 (2012): 952-958. https://doi.org/10.1016/i.jnoncrysol.2012.01.009

[4] Yousef, E., M. Hotzel, and C. Rüssel. "Effect of ZnO and Bi2O3 addition on linear and non-linear optical properties of tellurite glasses." Journal of Non-Crystalline Solids 353, no. $4 \quad$ (2007): 333-338. https://doi.org/10.1016/i.jnoncrysol.2006.12.009

[5] Henderson, M. R., B. C. Gibson, H. Ebendorff-Heidepriem, K. Kuan, S. Afshar V, J. O. Orwa, I. Aharonovich et al. "Diamond in tellurite glass: a new medium for quantum information." Advanced Materials 23, no. 25 (2011): $2806-$ 2810. https://doi.org/10.1002/adma.201100151

[6] El-Mallawany, Raouf A. H. Tellurite Glasses Handbook. CRC Press, Boca Raton, LLC, Florida, USA, 2002. 
[7] Philip, J., N. Rodrigues, M. Sadhukhan, A. K. Bera, and B. K. Chaudhuri. "Temperature dependence of elastic and dielectric properties of (Bi2O3) 1- x (CuO) x oxide glasses." Journal of Materials Science 35, no. 1 (2000): $229-233$. https://doi.org/10.1023/A:1004785809370

[8] Sun, Hong-tao, Lei Wen, Zhong-chao Duan, Li-li Hu, Jun-jie Zhang, and Zhong-hong Jiang. "Intense frequency upconversion fluorescence emission of Er3+/Yb3+-codoped oxychloride germanate glass." Journal of Alloys and Compounds 414, no. 1-2 (2006): 142-145. https://doi.org/10.1016/i.jallcom.2005.02.107

[9] Pavani, P. Gayathri, S. Suresh, and V. Chandra Mouli. "Studies on boro cadmium tellurite glasses." Optical Materials 34, no. 1 (2011): 215-220. https://doi.org/10.1016/i.optmat.2011.08.016

[10] Baki, Sharudin Omar, L. S. Tan, C. S. Kan, Halimah Mohamed Kamari, A. S. M. Noor, and Mohd Adzir Mahdi. "Spectroscopic Studies of Er3+-Yb3+ Codoped Multicomposition Tellurite Oxide Glass." Sains Malaysiana 43, no. 6 (2014): 843-850. https://doi.org/10.4028/www.scientific.net/AMR.895.323

[11] Mott, Nevill Francis, and Edward A. Davis. Electronic processes in non-crystalline materials: 2nd ed. Oxford, Clarendon Press, New York, Oxford University Press, 1979.

[12] Baki, S. O., L. S. Tan, C. S. Kan, Mohamed Kamari Halimah, and M. A. Mahdi. "Structural and Optical Characteristics of Erbium Doped Ternary TeO2-TiO2-Bi2O3 Glasses." In Solid State Phenomena, vol. 268, pp. 148-154. Trans Tech Publications Ltd, 2017. https://doi.org/10.4028/www.scientific.net/SSP.268.148

[13] Baki, S. O., L. S. Tan, C. S. Kan, H. M. Kamari, A. S. M. Noor, and M. A. Mahdi. "Structural and optical properties of Er3+-Yb3+ codoped multicomposition TeO2-ZnO-PbO-TiO2-Na2O glass." Journal of Non-Crystalline Solids 362 (2013): 156-161. https://doi.org/10.1016/i.jnoncrysol.2012.11.042

[14] Zhao, Shilong, X. L. Wang, S. Q. Xu, and L. L. Hu. "Frequency upconversion fluorescence of Er3+-doped TeO2-WO3 glass." Chalcogenide Lett 2, no. 10 (2005): 99-102. https://doi.org/10.1016/i.matchemphys.2005.10.011

[15] Tanabe, S., T. Ohyagi, N. Soga, and T. Hanada. "Compositional dependence of Judd-Ofelt parameters of Er 3+ ions in alkali-metal borate glasses." Physical Review B 46, no. 6 (1992): 3305. https://doi.org/10.1103/PhysRevB.46.3305

[16] Zhao, Xinyu, Xiaoli Wang, Hai Lin, and Zhiqiang Wang. "Electronic polarizability and optical basicity of lanthanide oxides." Physica B: Condensed Matter 392, no. 1-2 (2007): 132-136. https://doi.org/10.1016/i.physb.2006.11.015

[17] Dimitrov, Vesselin, and Takayuki Komatsu. "Classification of oxide glasses: a polarizability approach." Journal of Solid State Chemistry 178, no. 3 (2005): 831-846. https://doi.org/10.1016/i.jssc.2004.12.013

[18] Ohishi, Y., S. Mitachi, T. Kanamori, and T. Manabe. "Optical absorption of 3d transition metal and rare earth elements in zirconium fluoride glasses." Physics and Chemistry of Glasses 24, no. 5 (1983): 135-140.

[19] Sidek, H. A. A., S. Rosmawati, Z. A. Talib, M. K. Halimah, and W. M. Daud. "Synthesis and optical properties of ZnOTeO 2 glass system." American Journal of Applied Sciences 6, no. 8 (2009): 1489. https://doi.org/10.3844/ajassp.2009.1489.1494 